\title{
Salivary beta amyloid protein levels are detectable and differentiate patients with Alzheimer's disease dementia from normal controls: preliminary findings
}

\author{
Marwan N Sabbagh ${ }^{1,2^{*}}$, Jiong Shi ${ }^{1}$, Moonhee Lee ${ }^{3}$, Lisa Arnold ${ }^{1}$, Yazan Al-Hasan ${ }^{1}$, Jennifer Heim ${ }^{1}$
} and Patrick McGeer ${ }^{3}$

\begin{abstract}
Background: Peripheral diagnostics for Alzheimer's disease (AD) continue to be developed. Diagnostics capable of detecting $A D$ before the onset of symptoms are particularly desirable, and, given the fact that early detection is imperative for alleviating long-term symptoms of the disease, methods which enable detection in the earliest stages are urgently needed. Saliva testing is non-invasive, and saliva is easy to acquire. A simple, non-invasive saliva test can potentially be used as an adjunct to diagnose AD during its earliest stages.

Methods: Salivary levels of beta amyloid $42\left(A \beta_{42}\right)$ were quantitated with enzyme-linked immunosorbent-type assays. Fifteen AD patients (7 men, mean age 77.8 \pm 1.8 years, mean Mini-Mental State Examination [MMSE] score $19.0 \pm 1.3$ ) and 7 normal controls ( 2 men, mean age $60.4 \pm 4.7$ years, mean MMSE $29.0 \pm 0.4$ ) were enrolled.

Results: Salivary $A \beta_{42}$ levels were significantly higher in $A D$ patients than in controls $(51.7 \pm 1.6 \mathrm{pg} / \mathrm{mL}$ for $A D$ and 21.1 $\pm 0.3 \mathrm{pg} / \mathrm{mL}$ for controls, $p<0.001$ ). Based on these results, saliva testing appears to be a promising method for detecting AD during its critical early stages.
\end{abstract}

Keywords: Alzheimer's disease, Beta amyloid, Biomarker, Dementia, Saliva

\section{Background}

The need for a rapid screening method to predict the risk of Alzheimer's disease (AD) remains an important objective that would inform the decision to initiate early therapy and mitigate the long-term effects and devastating sequelae of advanced AD. Current results of an early objective index have failed to provide a realistic and reasonable screening method. Successful treatment of AD will ultimately depend upon early intervention. In turn, early intervention will depend on detection even before the onset of clinical symptoms. Ideally, biomarker-driven screening could be used for its negative predictive value (i.e., to screen out patients with a low probability of progression).

\footnotetext{
* Correspondence: sabbagm@ccf.org

'Department of Neurology, Barrow Neurological Institute, St. Joseph's

Hospital and Medical Center, Phoenix, AZ, USA

${ }^{2}$ Cleveland Clinic Lou Ruvo Center for Brain Health, 880 W. Bonneville Rd, Las Vegas, Nevada, NV 89106, USA

Full list of author information is available at the end of the article
}

Peripheral diagnostics for AD continue to be developed and tested. Biomarkers are urgently required for early detection, before clinical signs appear. To date, biomarkers that may detect $\mathrm{AD}$ in its early stages involve expensive and invasive procedures. These biomarkers include cerebrospinal fluid analyses of beta amyloid 42 $\left(\mathrm{A} \beta_{42}\right)$, tau, and phosphorylated tau, [1] as well as positron emission tomography scanning for $A \beta$ deposits or tau deposition using mostly fludeoxyglucose (F18) compounds. Although these biomarkers have relatively high specificity and sensitivity, the testing cost is high and access is limited. Recently, the focus has shifted to neurogranin in cerebrospinal fluid.

Biomarkers derived from plasma, serum, and urine has all been explored. Detectable levels of $A \beta_{42}$ in plasma have been reported with variable results. $[2,3]$ The recent $\mathrm{Na}$ ture paper demonstrates the utility of assessing plasma $A \beta$ and APP fragments using immunoprecipitation techniques 
in two separate cohorts from Japan and Australia with very high specificity and sensitivity and correlating the values to PIB PET [4]. Recent studies have reported detection of plasma tau using two different techniques. [5, 6]

A cheap, non-invasive indicator would be an extremely valuable asset for physicians and for patients and their families. A test using saliva is appealing because it is relatively easy to acquire and is non-invasive. $A \beta_{42}$ levels in saliva show promise of being such a biomarker.

Lee et al. [7] demonstrated the feasibility of detecting $\mathrm{A} \beta_{42}$ in saliva and other tissues. Bermejo-Pareja et al.[87] analyzed 126 saliva samples from AD cases and controls, as well as 51 saliva samples from Parkinson disease patients. They found that $A \beta_{42}$ levels were significantly elevated in patients with mild to moderate $\mathrm{AD}$ but not in patients with severe AD. They found no significant difference between Parkinson disease patients and controls. Mean levels of $A \beta_{42}$ were $2.9-11.70 \mathrm{pg} / \mathrm{mL}$ of saliva. Mean proteins averaged $6.6 \mu \mathrm{g} / \mathrm{mL}$ of saliva. They also measured $A \beta_{40}$ levels in saliva. These values were in the range of $21-26 \mathrm{pg} / \mathrm{mL}$ of saliva, but no differences were found between $\mathrm{AD}$ patients and controls.

We report the detection of salivary $A \beta_{42}$ in prospectively characterized $\mathrm{AD}$ patients and controls who were assessed in a memory disorders clinic to demonstrate the feasibility of the use of the protocol and the assay in clinical practice.

\section{Methods}

\section{Subjects}

Fifteen prospectively evaluated patients with mild to moderate $\mathrm{AD}$ were enrolled. All 15 met the $\mathrm{AD}$ criteria established by the National Institute on Aging and the Alzheimer's Association (NIA-AA) [9]. Inclusion criteria were Mini-Mental State Examination (MMSE) scores of $10-26$ and age $\geq 50$ years. For comparison, 8 healthy patients with normal cognitive functioning were included as controls. The controls had no dementia or cognitive impairment and no neurodegenerative disease; they were intact functionally, physically, and socially; were age $\geq$ 50 years; and had MMSE scores $\geq 28$. We excluded subjects with a medical history of major systemic diseases that could possibly affect cognitive function including other dementias (e.g. DLB, FTD, PPA, PDD, VAD), such as cardiopulmonary failure, hepatic or renal failure, diabetes mellitus, head injury, stroke, or other neurodegenerative disease.

\section{Approval of human subject protocol}

The study was conducted in accordance with the human subject study protocol approved by the Institutional Review Board at Barrow Neurological Institute, St. Joseph's Hospital and Medical Center, Phoenix, Arizona. The recruitment and informed consent process were conducted by qualified personnel in the Alzheimer's and Memory
Disorders Center at Barrow Neurological Institute. Informed consent was obtained from each participant.

\section{Specimen collection}

Saliva specimens were collected from all 15 patients and all 8 controls. Participants were asked to spit directly into a collection tube labeled with a unique identifier for each participant. The saliva was collected passively (passive drool) without any stimulant or stimulation. Immediately after collection, specimens were stored at room temperature until shipment, as described below.

Specimens were batch shipped via ambient shipment to Aurin Biotech, Inc., and the University of British Columbia under a signed materials transfer agreement. Upon receipt at Aurin or the University, specimens were analyzed immeditely. Residual specimens may be stored at 4 degrees Celsius for up to 1 year after collection..

\section{Laboratory analysis}

Saliva specimens were stored at room temperature until analyzed. The protocol described by Lee et al. [7] was used. Briefly, the $A \beta_{42}$ level in the saliva samples was determined by first adding $2-3 \mathrm{~mL}$ of saliva to tubes containing $0.5 \mathrm{mg}$ thioflavine $\mathrm{S}$ (Sigma-Aldrich Corp., St. Louis, MO), to prevent $A \beta_{42}$ aggregation. Then $0.5 \mathrm{mg}$ sodium azide (Thermo Fisher Scientific, Inc., Suwanee, GA) was added to prevent bacterial growth. In typical assays, amounts of the saliva mixture varying from 0 (control) to $300 \mu \mathrm{L}$ were added to the microwells, and enzyme-linked immunosorbent assay (ELISA)-type assays (Aurin Biotech, Inc.) were carried out as described by Lee et al. [7]. Each sample was analyzed in triplicate.

\section{Statistical analysis}

We used the t-test for comparing differences in mean values for the two groups. Data are reported as means and SDs. Significance was defined as $p<0.05$. An ANCOVA analysis was conducted with Abeta as the dependent variable and age as the covariate..

\section{Results}

The mean age of the $15 \mathrm{AD}$ patients $(7$ men and 8 women) was $77.8 \pm 1.8$ years, and the mean age of the 7 controls ( 2 men, 5 women) was $60.4 \pm 4.7$ years. The mean MMSE scores for the patients and controls were $19.0 \pm 1.3$ and $29.0 \pm 0.4$, respectively. The AD patients were significantly older $\left(\mathrm{t}_{20}=4.25, p<0.05\right)$ and more impaired per their MMSE scores $\left(t_{19}=5.53, p<0.05\right)$ than controls.

After saliva levels were stabilized and mixed with an anti-bacterial agent, we quantitated the $A \beta_{42}$ in a series of samples using ELISA-type assays (Aurin Biotech, Inc.). The $A \beta_{42}$ levels in saliva were found to be significantly higher in $\mathrm{AD}$ patients than in controls (51.7 \pm 
$1.6 \mathrm{pg} / \mathrm{mL}$ for $\mathrm{AD}$ patients and $21.1 \pm 0.3 \mathrm{pg} / \mathrm{mL}$ for controls, $p<0.05)$ (Fig.1a). The intra assay coefficient of variation $(\mathrm{CV})$ was 3.10 for $\mathrm{AD}$ and 1.34 for controls. When the ANCOVA was performed controlling for age, age was not significant $\left(\mathrm{F}_{1,18}=0.02, p=0.884\right)$. (Fig.1b).

\section{Discussion}

The results of this study demonstrate and reinforce the feasibility of prospectively collecting and analyzing saliva for the detection and quantification of salivary $A \beta_{42}$. Our analysis of the quantification of $A \beta_{42}$ in the saliva of patients with mild to moderate $A D$ compared to $A \beta_{42}$ in the saliva of controls demonstrated that $\mathrm{AD}$ patients had a 2.45 -fold increase in $A \beta_{42}$. Thus, the saliva levels of $\mathrm{A} \beta_{42}$ were significantly higher $\left(t_{20}=12.8, p=2.8 \times 10^{-4}\right)$ in $\mathrm{AD}$ patients than in controls. This adds to the previous reports [6] in several ways. First, it demonstrates the feasibility of salivary specimen collection for the detection of $A \beta_{42}$. Second, it shows that the assay is reproducible in that the cohort used in this report does not overlap at all with the first report. Third, the current cohort uses a prospectively characterized clinical sample.

The use of salivary $A \beta_{42}$ as a biomarker for $A D$ is highly innovative compared to more traditional detection methods (cerebrospinal fluid, imaging, and blood studies). The results of this simple, non-invasive test

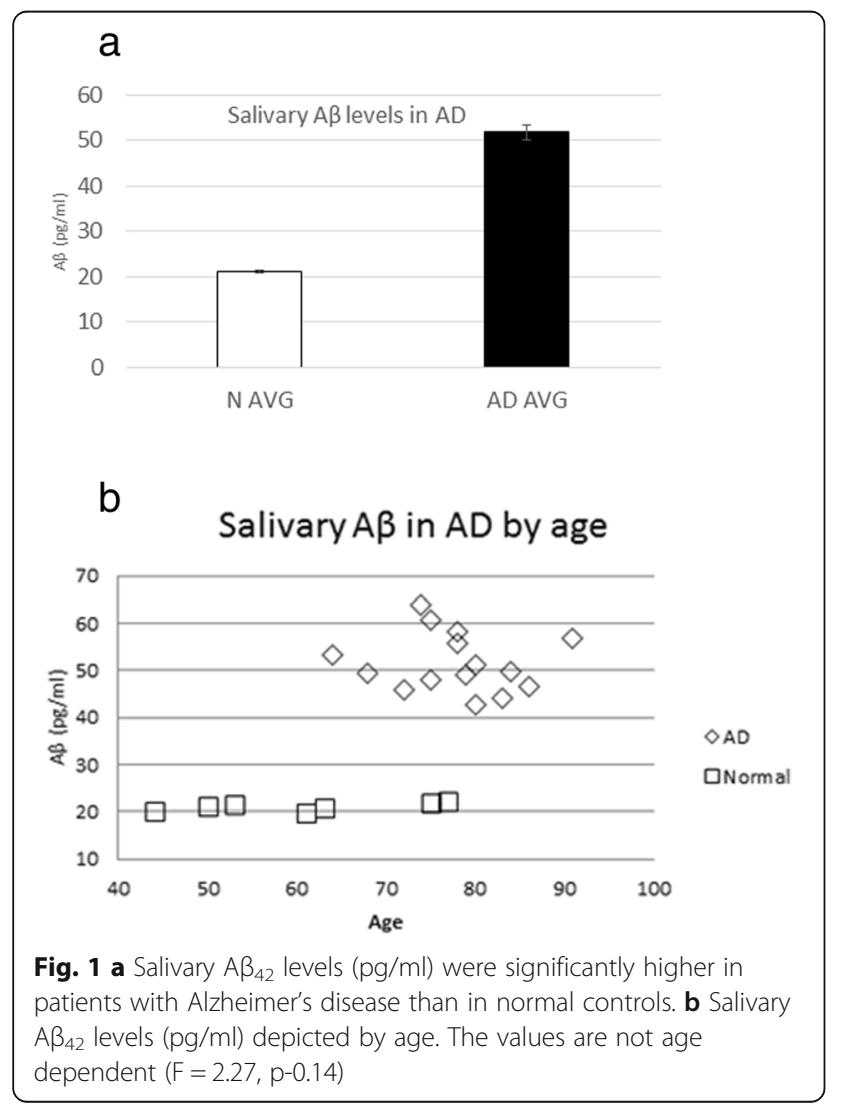

indicate its potential use as an adjunct for the diagnosis of $\mathrm{AD}$ or as a screening measure for its negative predictive value to exclude patients with a low probability of disease progression.

The test described measures salivary levels of $A \beta$ terminating at position $42\left(A \beta_{42}\right)$. Previous studies have found $A \beta_{42}$ to be produced in other organs [Lee et al. 2017 7], thus establishing the generality of its production. Brain deposits of this peptide are characteristic of AD. Biomarker studies indicate that these brain deposits commence a decade or more before the clinical onset of AD. Similar to the results of other studies, $[7,8]$ our findings indicate that $A \beta_{42}$ is elevated in the saliva of patients with $\mathrm{AD}$. Thus, our data support elevated salivary $\mathrm{A} \beta_{42}$ as a potential biomarker for AD. The current study replicates the findings of Lee et al. [7] is the amount of amyloid detected is $>2 \times$ higher in AD compared to NC. These differences are larger than the differences reported by Bermejo-Pareja [8] possibly because the assay method differs somewhat.

Our report contrasts with previous studies. Shi et al. [10] used high sensitivity mass spectrometry to detect salivary $A \beta$ and tau. They found that salivary tau was elevated but $A \beta_{42}$ was not detectable. How can these findings be explained? Mass spectrometry is able to detect the molecular weights of the proteins. Since there are multiple forms of $A \beta$, the mass spec might not be detecting the species of $A \beta$ that we are detecting in our study. The main difference in accounting for the detectable $A \beta$ in our study is that we used an ELISA assay with antibodies specifically able to bind to $A \beta_{42}$.

What these results do not indicate is the source of the $A \beta$. Is $A \beta_{42}$ endogenous to the salivary gland? Future studies might want to explore the histology of salivary glands to determine if salivary glands produce $\mathrm{Ab}$ forms similar to the CNS. Amyloid is produced in detectable amounts in a variety of organs [7]. Identifying the source will be important in determining the clinical utility.

In this study, we find that age did not affect the findings even when controlled for. The group of controls in our study was significantly younger than the group of $\mathrm{AD}$ patients $(60.4 \pm 4.7$ years vs. $77.8 \pm 1.8$ years, $p<0.05)$. In contrast, in the Lee et al. [7] study, almost identical levels of salivary $A \beta_{42}$ were found in $A D$ patients and controls aged 15 to 92 years.

Does salivary $A \beta_{42}$ reflect the level of $A \beta$ in the central nervous system? Does salivary $A \beta_{42}$ come from another source? Future studies will explore the source. Future studies will involve collecting saliva specimens across all adult age groups to analyze, compare, and determine the stability of $A \beta_{42}$ by age. Future studies will also assess the specificity and sensitivity of the salivary test in patients with mild cognitive impairment, Lewy body disease, primary progressive aphasia, and Parkinson disease. Other 
studies to be completed include test-retest validity, and multi-lab assay validity for standardization.

Ultimately, the results of the salivary test for an individual will be correlated with the amyloid status of that person. Future studies will address a variety of questions: Is amyloid positivity associated with higher levels of $\mathrm{A} \beta_{42}$ ? Can the assay method be adapted to detect and quantify other biomarkers, such as tumor necrosis factor- $\alpha$, interleukin- 6 , and interleukin- $1 \beta$ ? Do salivary levels of $A \beta_{42}$ change with or correlate with the severity of dementia? Even more development is required, including test-retest validity, multi-laboratory validation, and identification of confounders of diurnal variations. Given the strength of the results from in this study, salivary $A \beta_{42}$ warrants further investigation as a potential biomarker for mild to moderate AD.

\section{Abbreviations}

AD: Alzheimer's disease; A 3 : beta amyloid; ELISA: enzyme-linked immunosorbent assay; MMSE: Mini-Mental State Examination; NIAAA: National Institute on Aging and Alzheimer's Association

\section{Acknowledgements}

The authors thank the staff of Neuroscience Publications at Barrow Neurological Institute for assistance with manuscript preparation. We wish to thank Ms. Angelica Garcia for specimen acquisition.

\section{Funding}

Barrow Neurological Foundation and NIA P30 AG019610 and Keep Memory Alive Foundation.

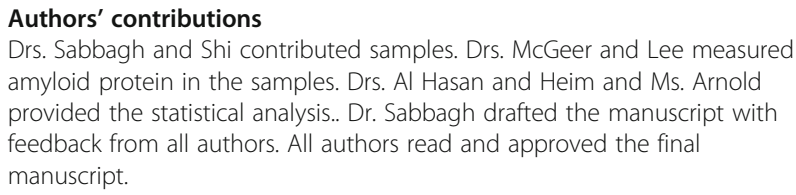
amyloid protein in the samples. Drs. Al Hasan and Heim and Ms. Arnold provided the statistical analysis.. Dr. Sabbagh drafted the manuscript with feedback from all authors. All authors read and approved the final manuscript.

\section{Ethics approval and consent to participate}

In manuscript.

\section{Consent for publication}

NA

\section{Competing interests}

Drs. McGeer and Lee have proprietary interests in Aurin Biotech, Inc. Drs. Sabbagh, Shi, and Al-Hasan, Heim, and Ms. Arnold do not.

\section{Publisher's Note}

Springer Nature remains neutral with regard to jurisdictional claims in published maps and institutional affiliations.

\section{Author details}

${ }^{1}$ Department of Neurology, Barrow Neurological Institute, St. Joseph's Hospital and Medical Center, Phoenix, AZ, USA. ${ }^{2}$ Cleveland Clinic Lou Ruvo Center for Brain Health, 880 W. Bonneville Rd, Las Vegas, Nevada, NV 89106, USA. ${ }^{3}$ Aurin Biotech, Vancouver, BC, USA.

Received: 11 September 2017 Accepted: 20 September 2018 Published online: 26 September 2018

\section{References}

1. Blennow K. A review of fluid biomarkers for Alzheimer's disease: moving from CSF to blood. Neurol Ther. 2017;6:15-24.
2. Yaffe K, Weston A, Graff-Radford NR, et al. Association of plasma betaamyloid level and cognitive reserve with subsequent cognitive decline. JAMA. 2011;305:261-6.

3. Roberts KF, Elbert DL, Kasten TP, et al. Amyloid-beta efflux from the central nervous system into the plasma. Ann Neurol. 2014;76:837-44.

4. Nakamura A, Kaneko N, Villemagne VL, Kato T, Doecke J, Doré V, Fowler C, Li QX, Martins R, Rowe C, Tomita T, Matsuzaki K, Ishii K, Ishii K, Arahata Y, Iwamoto S, Ito K, Tanaka K, Masters CL, Yanagisawa K. High performance plasma amyloid- $\beta$ biomarkers for Alzheimer's disease. Nature. 2018; 554(7691):249-54. https://doi.org/10.1038/nature25456 Epub 2018 Jan 31.

5. Lue L-F, Sabbagh MN, Walker DG, et al.: Plasma profiles of tau, amyloid $\beta 42$ and amyloid 40 analyzed by immunomagnetic reduction assays distinguished Alzheimer's disease from age-matched normal controls. Frontiers in Neurosciences $=$, In Press.

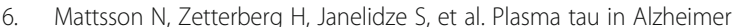
disease. Neurology. 2016;87:1827-35.

7. Lee M, Guo JP, Kennedy K, et al. A method for diagnosing Alzheimer's disease based on salivary amyloid-beta protein 42 levels. J Alzheimers Dis. 2017:55:1175-82.

8. Bermejo-Pareja F, Antequera D, Vargas T, et al. Saliva levels of Abeta1-42 as potential biomarker of Alzheimer's disease: a pilot study. BMC Neurol. 2010; 10(108)

9. McKhann GM, Knopman DS, Chertkow H, et al. The diagnosis of dementia due to Alzheimer's disease: recommendations from the National Institute on Aging-Alzheimer's association workgroups on diagnostic guidelines for Alzheimer's disease. Alzheimers Dement. 2011;7:263-9.

10. M S, Sui YT, Peskind ER, Li G, Hwang H, Devic I, Ginghina C, Edgar JS, Pan C, Goodlett DR, Furay AR, Gonzalez-Cuyar LF, Zhang J. Salivary tau species are potential biomarkers of Alzheimer's disease. J Alzheimers Dis. 2011;27(2): 299-305. https://doi.org/10.3233/JAD-2011-110731.

Ready to submit your research? Choose BMC and benefit from

- fast, convenient online submission

- thorough peer review by experienced researchers in your field

- rapid publication on acceptance

- support for research data, including large and complex data types

- gold Open Access which fosters wider collaboration and increased citations

- maximum visibility for your research: over $100 \mathrm{M}$ website views per year

At $\mathrm{BMC}$, research is always in progress.

Learn more biomedcentral.com/submission 